\title{
DETERMINATION OF TIMING PARAMETERS OF DUST CLOUDS EXPLOSION IN DEPENDENCE ON THE SIZE OF THE VESSEL VOLUME
}

\author{
Richard KURACINA ${ }^{1}$, Zuzana SZABOVÁ ${ }^{1}$ \\ ${ }^{1}$ Slovak University OF TECHNOLOGY IN BRATISLAVA \\ FACUlTY OF MATERIALS SCIENCE AND TECHNOLOGY IN TRNAVA, \\ INSTITUTE OF INTEGRAL SAFETY \\ ULICA JÁNA BOTTU 2781/25, 91724 TRNAVA, SLOVAK REPUBLIC \\ e-mail: richard.kuracina@stuba.sk, zuzana.szabova@stuba.sk \\ Received 28 April 2021, Accepted 26 May 2021, Published 20 July 2021
}

\begin{abstract}
EN 14034 standard defines the requirements for igniter, to determine the properties of dust clouds. The standard specifies the conditions for occurrence of explosions of dust clouds. According to the standard, equipment with a volume of $1 \mathrm{~m} 3$ and $20 \mathrm{~L}$ can be used to determine the explosion parameters of dispersed dusts. The equipment has the time parameters of dispersing and the ignition system defined in the Standard. Experimental determination of time parameters is required for a different chamber volume. The article therefore deals with the determination of parameters for dispersing system in the 291 litre chamber. Determination of igniter delay was performed on the base of setting the time relay. Activation of pressurised air flow was determined by calculation, and it was subsequently experimentally verified in laboratory conditions. A video camera recording was selected for measuring the rate of nitrocellulose ignition from the resistance wire. The result of this study is determination of the igniter timing in dependence of the explosion chamber volume. The time delay of the nitrocellulose igniter is $320 \mathrm{~ms}$.
\end{abstract}

\section{Keywords}

Nitrocellulose, ignition, resistance wire, dust clouds explosion, timing parameters

\section{INTRODUCTION}

Industrial explosions have been a hazard as long as man has been processing, storing and transporting materials. Managing explosion hazards involves first characterization of the explosion properties of materials through testing. Once characterized, the hazard can be managed through clear determination of the prevention and protection objectives, followed by selection and implementation of the appropriate protection method(s). 
Dust explosions have accounted for numerous deaths, disappearance of companies, and large financial losses; yet they represent one of the least recognized of industrial fire hazards. They can occur within any process where a combustible dust is handled, produced or stored, and can be triggered by any energy source, including static sparks, friction and incandescent material [1].

Dust explosions in the process industries practically always start inside the process equipment such as mills, dryers, mixers, classifiers, conveyors, and storage silos and hoppers. For any given dust type, the ease with which dust clouds ignite and the rates with which they burn vary considerably with the factors well-known in powder science and technology. The key factors include the primary particle size distribution of the dust, the degree of de-agglomeration of the dust particles in the cloud, the dust concentration distribution in the cloud, and the cloud turbulence. The last three factors entirely depend on the actual process situation in which the dust cloud is generated and sustained. The paper [2] discusses influence of those factors. The issues of dispersed dust clouds explosion in the process industries are dealt e.g. by the authors $[3,4,5,6,7]$.

Safety characteristics are essential for the determination of explosion hazards during handling of combustible dusts and for the design of safety measures. The safety characteristics of Maximum Explosion Pressure $\mathrm{P}_{\max }$, Maximum Explosion Pressure Rise (dp/dt) $\max$ and Lower Explosion Limit LEL are determined in closed vessels, such as the 20-L-sphere. Tests are preformed according to international Standards, for example of the EN 14034 series (2011) or ASTM E1226 (2012) [8].

Dust explosions occur when such dust is dispersed in the air as a cloud, and reacts with oxygen in the presence of an ignition source, while generating a violent combustion reaction in the form of flame propagation. These materials include the agricultural and food products (grain, malt, flour, maize starch, sugar, etc.), synthetic organic materials (plastics, pigments, pesticides, etc.), metals (aluminium, magnesium, etc.) and coal [9].

A dust explosion needs to be triggered by an ignition source of sufficient energy, and also requires the simultaneous presence of dust clouds of appropriate concentration as well as an atmosphere containing enough oxygen to permit combustion. The combustion process leads to a rapid and significant increase in pressure, typically up to 700 - $1000 \mathrm{kPa}$ within a confined space [10].

Several authors [11] have studied the influence of ignition delay on explosion characteristics of corn dust in air. Cashdollar and Zlochower [12] found that explosion characteristics depended on flow of dust in the experimental chamber. It is reported [13] that the explosion characteristics were a function of time. However, it is difficult to observe the flow in the experimental chamber. The ignition delay (the time interval between the onset of dust dispersion and the activation of ignition of dust/air mixture) has a significant effect on explosion characteristics [14].

In accordance with the previous studies, an ignition delay time of $60 \mathrm{~ms}$ in the 20-L sphere should generate almost the same level of turbulence of a $600 \mathrm{~ms}$ delay time in a $1 \mathrm{~m}^{3}$ vessel. However, other researchers have found that different ignition delay time values should be used in a 20-L sphere. Van der Wel [15] found that a delay time of $60 \mathrm{~ms}$ did not generate the same level of turbulence as in the $1 \mathrm{~m}^{3}$ vessel at $600 \mathrm{~ms}$, which suggested that about $165 \mathrm{~ms}$ should be used. Dahoe [16] found that the ignition delay time should be about $200 \mathrm{~ms}$.

The EN 14034 Standard defines the delay of igniter triggering against the activation of dispersing system for two chamber sizes $-1 \mathrm{~m}^{3}$ and 201 . The delay specified by Standard is thus $0.6 \mathrm{~s}$ in the first case, and $0.06 \mathrm{~s}$ in the other case. The EN 14034 Standard defines the requirements for ignition of dust mixture in an enclosed test space as follows: ignition source consists of two electrically activated pyrotechnic igniters, each of $5 \mathrm{~kJ}$ ignition power. The igniters must produce a dense cloud of very hot particles at their activation with a bit of gas. 
The igniters are fired by the electric fuse heads. The feed circuit of igniters must be capable of firing the detonators within less than $10 \mathrm{~ms}$. Both igniters must be placed in the centre of the explosion vessel, and must be fired in opposite directions [17].

These are the conditions required by the EN 14034 Standard. However, equipment in our laboratory does not provide such parameters, since the volume of the used chamber is 291 litres, and the igniter makes use of a resistance wire of a defined length as the ignition source [18]. It is therefore necessary to determine the timing parameters of dispersing system to meet the requirements of Standards.

Modification of these conditions for the purposes of our Institute workplace consists in the fact that no detonators but a resistance wire of a defined length is used as the source of ignition [18]. In order to secure the requirement of $10 \mathrm{~ms}$ firing time, it was necessary to perform the measurement allowing to determine the time of nitrocellulose ignition from the instant of trigging the circuit of resistance wire.

\section{METHODS AND EQUIPMENT}

The timing of individual parts of dispersing system was measured in several ways. The optimum time for delay of igniter triggering was determined, and the time for activation of pressurised air flow by the fast-opening valve was determined by calculation with approval by use of a pressure sensor at the end of inlet tube, and finally the burning in igniter was determined by a high-speed video camera.

Determination of igniter delay was conducted in the chamber on the base of setting the time relay. During the process of determination, the dust of beech wood was dispersed, whereas the time providing the maximum value of explosion pressure was considered for the optimum one.

Activation of the pressurised air flow was determined by calculation, and it was subsequently experimentally verified in the laboratory conditions. The calculation was based on the flow velocity of pressurised air streaming through the tube of small length. Approval in the laboratory conditions was performed in such a manner that a pressure transducer was attached to the end of a dispersing tube, and the time for starting the moment of sample dispersion was determined on the base of the pressure record after opening the fast-opening valve with an air reservoir pressurised to 9.5 bar. Scheme of the experiment is shown in Figure 1.

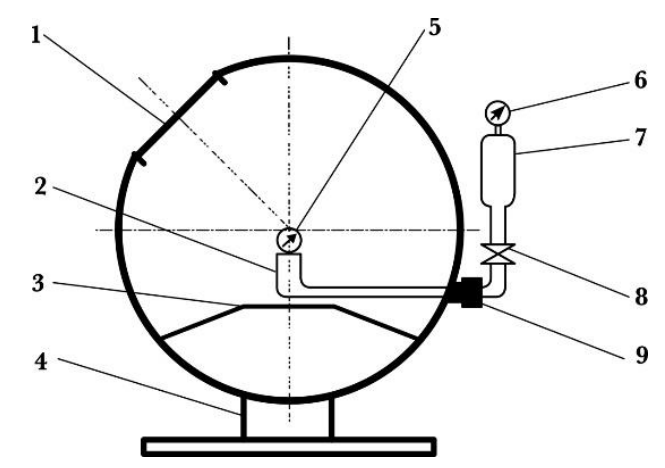

Figure 1 Measuring the valve opening. 1 - chamber cover, 2 - inlet tube of dispersing device, 3 - chamber bottom, 4 - stand, 5 - pressure transducer, 6 - manometer, 7 - reservoir of pressurised air, 8 - fast-opening valve, 9 - chamber bushing

A video camera recording was selected for measuring the rate of ignition from a resistance wire. Nitrocellulose used for the needs of igniter was dried Synthesia's E24 industrial 
nitrocellulose [17]. The combustion heat (higher heating value) was determined (in bomb calorimeter) as the value of $10400 \mathrm{~kJ} / \mathrm{kg}$. As the power source for resistance wire, the $320 \mathrm{VA}$ transformer was used, supplying the power equivalent to $6.4 \mathrm{~A}$ at $48 \mathrm{~V}$ AC voltage to the ignition circuit. Diameter of resistance wire was $0.05 \mathrm{~mm}$, and its resistance in igniter was $12 \Omega$. These values will cause an instantaneous heating of wire.

An aluminum tube of a $40 \mathrm{~mm}$ diameter was used as an igniter. The resistance wire was led through the tube centre and clamped by two holders connected to the power source. Nitrocellulose was inserted to the tube in such a manner to secure a direct contact with the resistance wire. The scheme is shown in Figure 2.

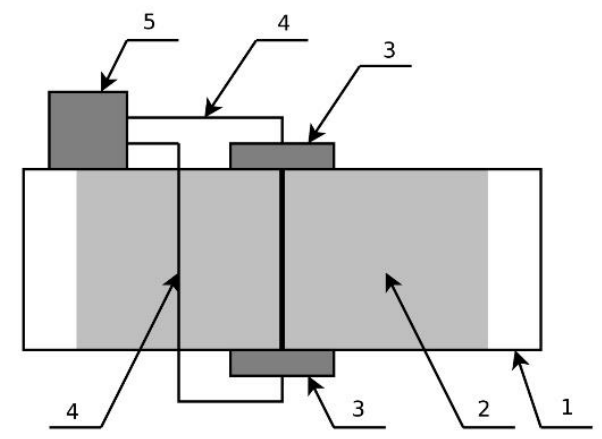

Figure 2 Scheme of igniter body (1 - aluminum tube of igniter, 2 - nitrocellulose charge, 3 - resistance wire holder, 4 - supply conductors, 5 - supply conductor holder)

According to the requirements of EN 14034 Standard, each part of igniter must produce the minimum energy of $5 \mathrm{~kJ}$. At the above-mentioned combustion heat, it is then necessary to load $1.00 \mathrm{~g}$ of nitrocellulose to each part of igniter: this amount of nitrocellulose will produce approximately 5 - 5.5 litres of gases at $300^{\circ} \mathrm{C}$. This volume of gases is negligible compared to the entire volume of the test chamber $(291$ 1). To determine the instant of igniter circuit triggering, a $12 \mathrm{~V}$ light diode was used. In the case of camera record, an ignition rate can be determined with $0.1 \mathrm{~ms}$ accuracy. Arrangement of components in the experiments is shown in Figure 3.
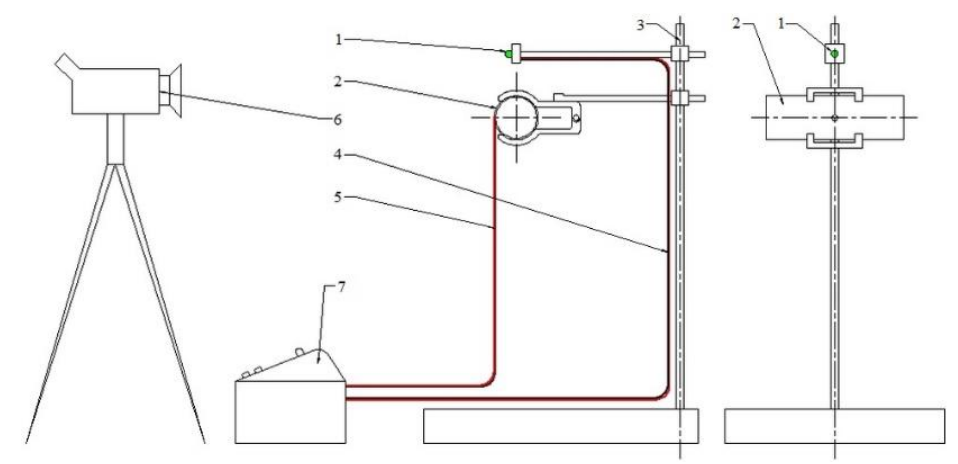

Figure 3 Scheme of arrangement of experimental apparatus (1 - checking diode, 2 - igniter, 3 - stand, 4 - conductors of checking diode, 5 - conductors of igniter, 6 - movie camera, 7 - power source)

\section{RESULTS}

\section{Delay of igniter activation}

The delay of igniter activation was investigated by using dry beech dust (obtained after sieving - size of particles ranging from 100 to 200 micrometres). Concentration of dust cloud 
was $150 \mathrm{~g} . \mathrm{m}^{-3}$ in all cases. The highest-pressure during explosion was recorded at the timing of $320 \mathrm{~ms}$, as shown in Figure 4.

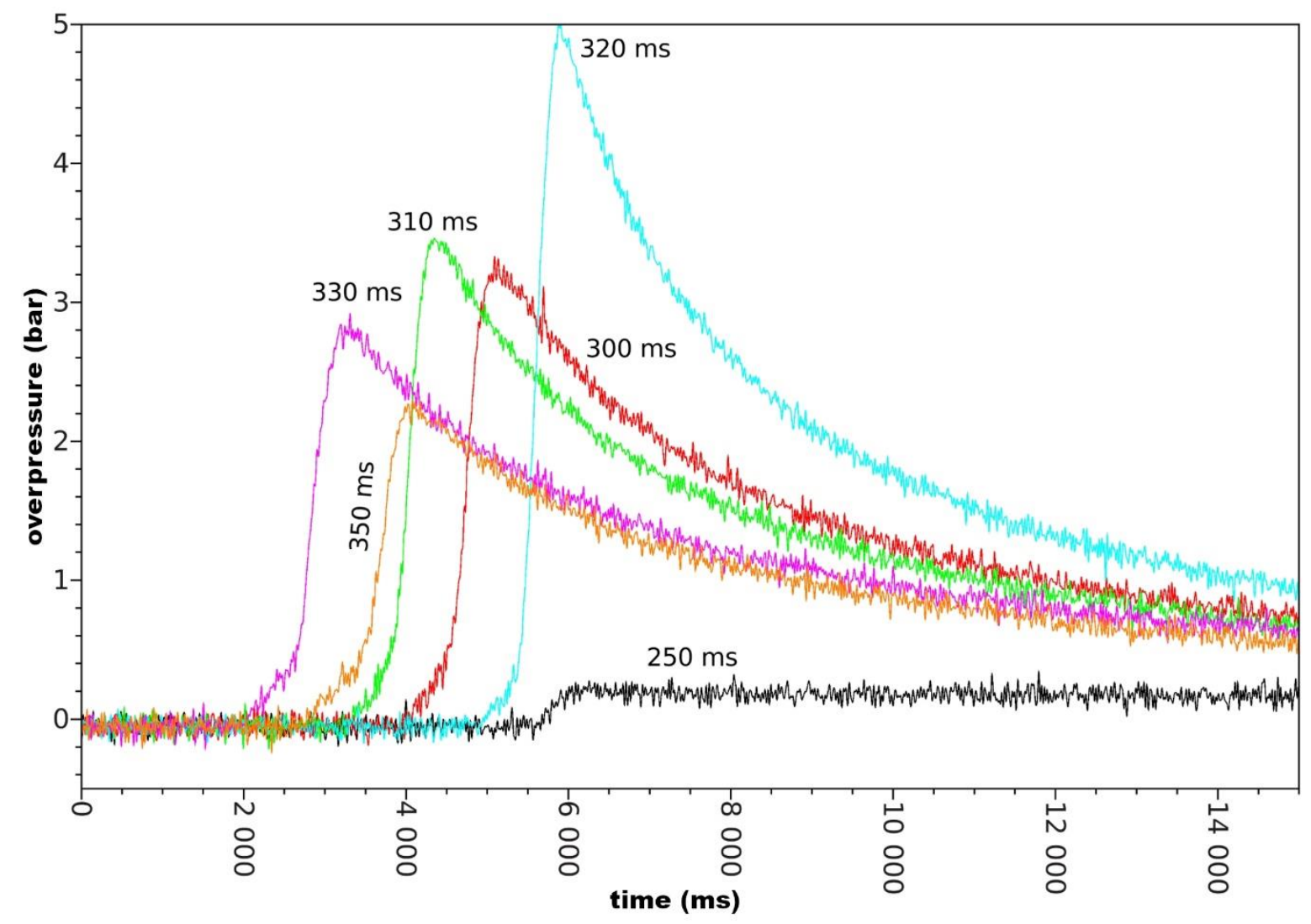

Figure 4 The explosion pressure of the beech dust with concentration of $150 \mathrm{~g} . \mathrm{m}^{-3}$ attained at different delays of igniter activation

\section{Start of fast-opening valve}

The velocity of air flow at the point of opening is supersonic. The sound velocity in the air at the opening point is:

$$
a_{0}=\sqrt{\frac{\gamma \cdot R \cdot T}{M}}=\sqrt{\frac{1.4 \cdot 8.31451 \cdot 293}{0.0288}}=343.9 \mathrm{~m} . \mathrm{s}^{-1},
$$

where $\gamma$ is the adiabatic constant of air, $\mathrm{R}$ is the gas constant, $\mathrm{T}$ is the thermodynamic temperature of the air and $\mathrm{M}$ is the average molar weight of the air. For the flow factor of supersonic streaming $\psi$, it is valid:

$$
\psi=\gamma\left(\frac{2}{\gamma+1}\right)^{\frac{\gamma+1}{2(\gamma-1)}}=1.4\left(\frac{2}{1.4+1}\right)^{\frac{1.4+1}{2(1.4-1)}}=0.810 .
$$

The mass velocity of the air streaming in the tube can be calculated by the relationship:

$$
G_{v}=C_{d} \frac{A \cdot p}{a_{0}} \psi=0.6 \frac{5.07 \cdot 10^{-4} \cdot 9.50 \cdot 10^{5}}{343.9} 0.810=0.680 \mathrm{~kg} . \mathrm{s}^{-1},
$$

where $\mathrm{C}_{\mathrm{d}}$ is the discharge coefficient (estimated on the base of materials and tube shape), $\mathrm{A}$ is the area of opening through which the gas is escaping, $\mathrm{p}$ is the pressure in the vessel, $\mathrm{a}_{0}$ is the sound velocity in the gas at escape point. Then the volume velocity of streaming at the supposed validity of ideal gas is: 


$$
\dot{V}=\frac{G_{V} \cdot R \cdot T}{M \cdot p}=\frac{0.680 \cdot 8.31451 \cdot 293}{0.0288 \cdot 9.5 \cdot 10^{5}}=60.50 \cdot 10^{-3} \mathrm{~m}^{3} \cdot \mathrm{s}^{-1},
$$

where $\mathrm{G}_{\mathrm{v}}$ is the mass velocity of air streaming. Then the streaming velocity $\mathrm{w}$ of the air in tubes is:

$$
w=\frac{\dot{V}}{A}=\frac{60.50 \cdot 10^{-3}}{5.07 \cdot 10^{-4}}=119.4 \mathrm{~m} . \mathrm{s}^{-1},
$$

where $\dot{V}$ is the volume velocity of streaming. The tube length 1 is 1 meter, then the time in which the air will pass through it is:

$$
\tau=\frac{l}{w}=\frac{1}{119.4}=8.37 \mathrm{~ms} .
$$

The time relay controlling the fast-opening valve was set to opening delay of $1000 \mathrm{~ms}$ since triggering the relay contact. The time since activation of the fast-opening valve up to start of gas dispersing is shown in Figure 6:

$$
\tau_{w}=1053.57-1000=53.57 \mathrm{~ms} .
$$

Figure 5 shows that the time for opening the fast-opening valve is $44.93 \mathrm{~ms}$. The following time for air streaming in the tube of dispersing device corresponds to this value:

$$
\tau_{0}=53.57-44.93=8.64 \mathrm{~ms} .
$$

This value corresponds to the calculated value of $8.37 \mathrm{~ms}$ ( $3.2 \%$ deviation).

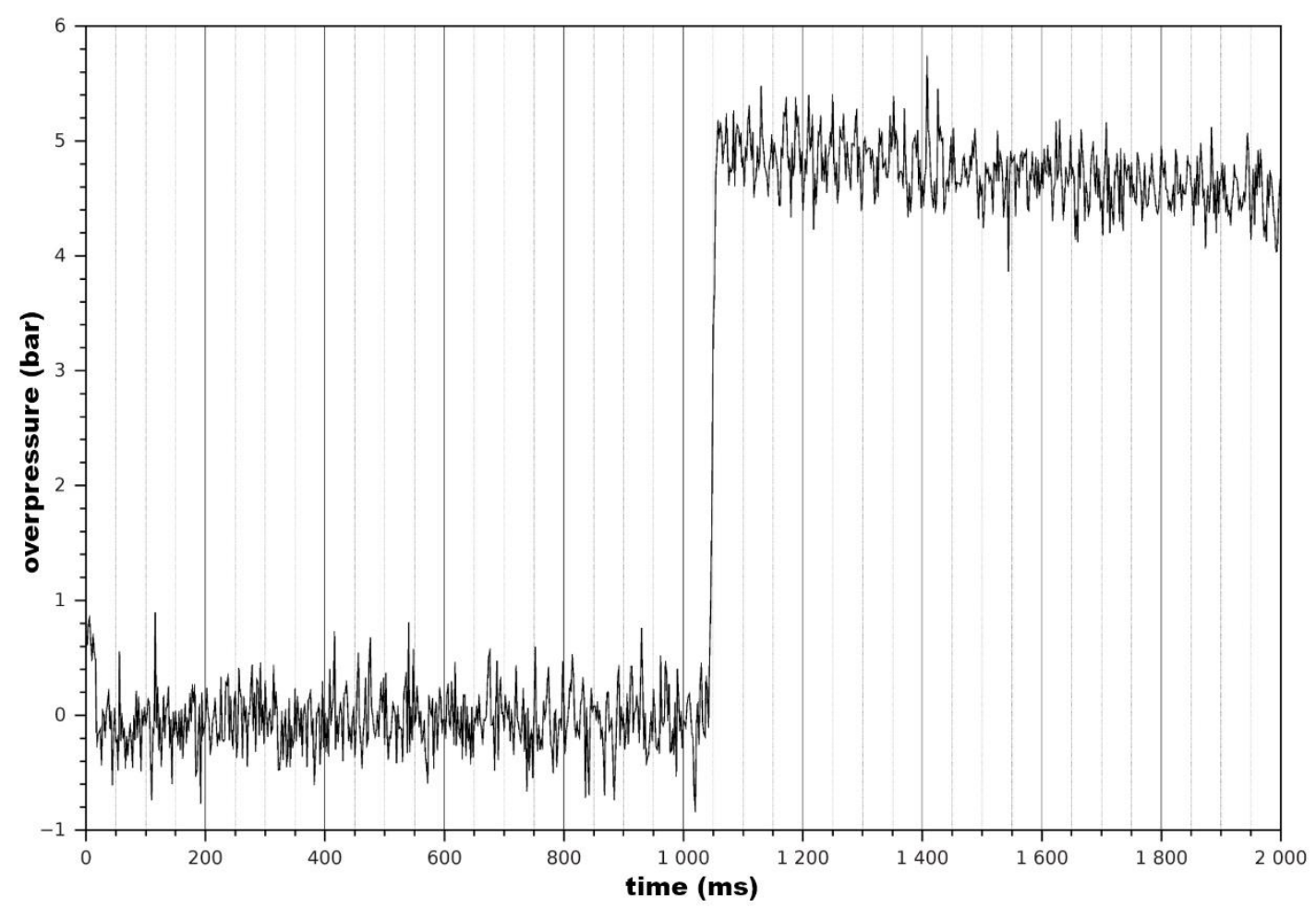

Figure 5 Pressure record of measurement of valve opening, circuit triggering in the time of $1000 \mathrm{~ms}$

\section{Rate of nitrocellulose ignition}

Based on the video camera record made at the recording frequency of $10000 \mathrm{fps}$, the rate of nitrocellulose ignition in igniter was calculated. The rate of events was determined on the basis of numbers of individual frames of video-record. Results of measurements based on the study of video-records are given in Table 1 below. 


\begin{tabular}{|l|l|}
\hline \multicolumn{2}{|c|}{ Table 1 Frames from video-record with significant events for igniter timing } \\
\hline \multicolumn{2}{|c|}{ Resistance wire } \\
\hline Frames range & Number $\mathbf{n}$ of frame \\
\hline LED on & $-2899-(-1514)$ \\
\hline First move of resistance wire & -2632 \\
\hline Visible heating of resistance wire & -2614 \\
\hline Burn of resistance wire & -2521 \\
\hline & -2395 \\
\hline Frames range & $-2498-(-1149)$ \\
\hline LED on & -2376 \\
\hline First visible flame on the right side of igniter & -1940 \\
\hline First visible flame on the left side of igniter & -1918 \\
\hline The same size of flame on both sides of igniter & -1727 \\
\hline
\end{tabular}

\begin{tabular}{|l|l|}
\hline Table 2 The results of ignition rate & Time (ms) \\
\hline Process & 1.8 \\
\hline Time to first move of resistance wire & 11.1 \\
\hline Time to visible heating of resistance wire & 23.7 \\
\hline Time to burn on of resistance wire & 43.6 \\
\hline Time to first visible flame on the right side of igniter & 45.8 \\
\hline Time to first visible blame on the left side of igniter & 64.5 \\
\hline Time to same size of flame on both sides of igniter & \\
\hline
\end{tabular}

Photos of ignition records are shown in Figure 6 a) $-d$ ).

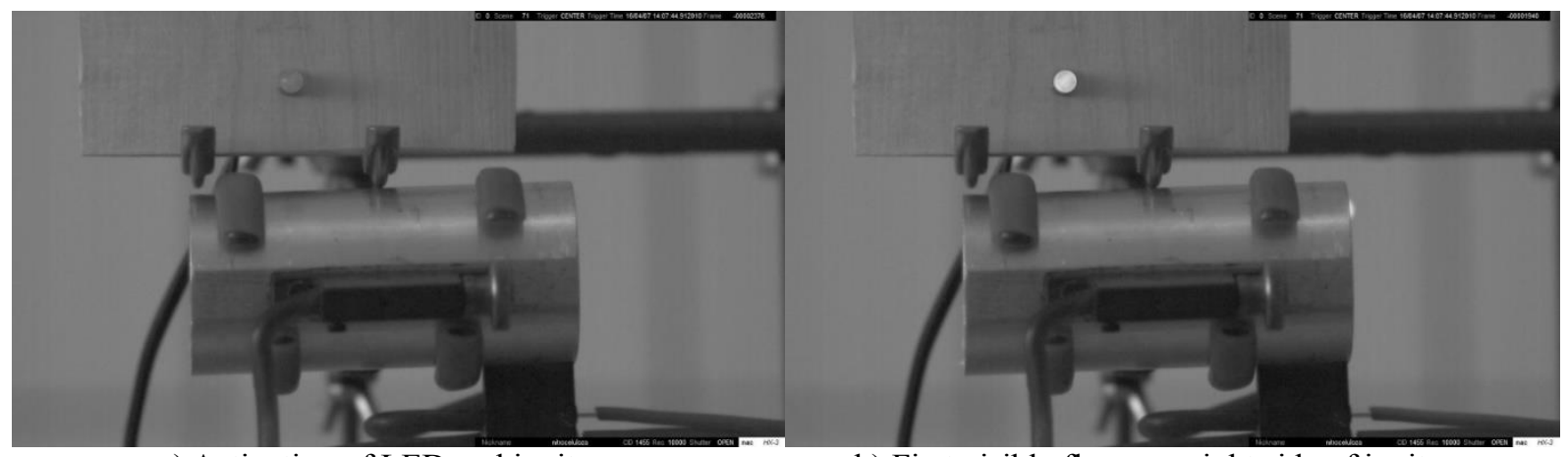

b) First visible flame on right side of igniter

a) Activation of LED and igniter

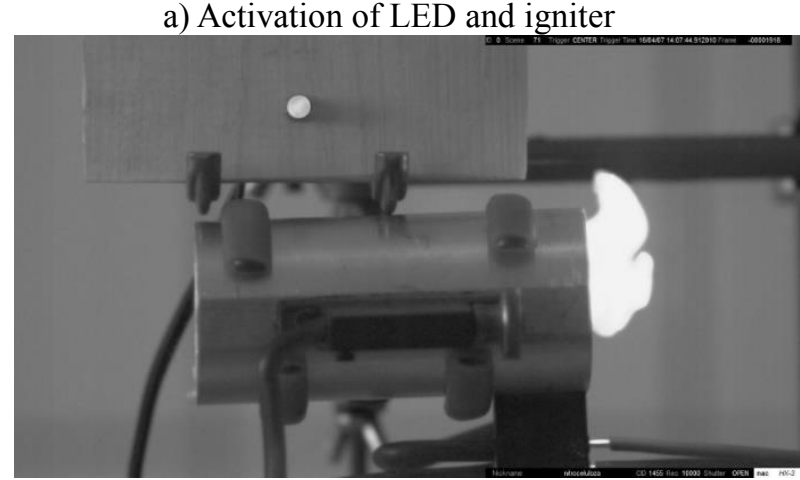

c) Flame on the right side of igniter

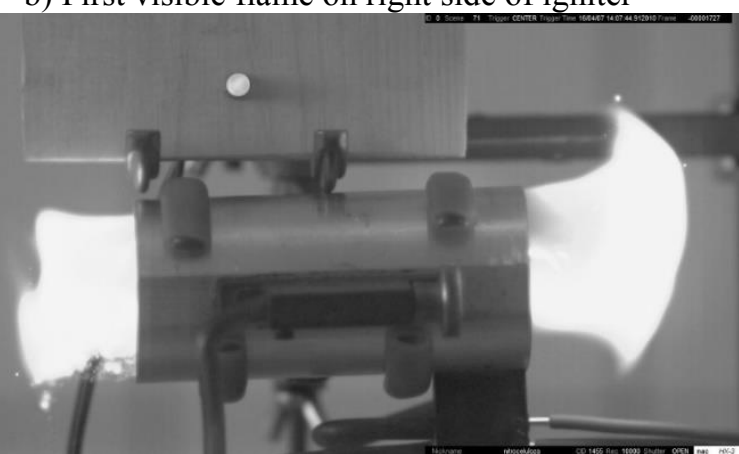

d) Flame on both sides of igniter

Figure 6 Nitrocellulose ignition in igniter body and flame flashing from the igniter tube 
Setting the timing for dispersing and ignition systems is an important element for observance of explosion of dust clouds. This is essential for obtaining the optimum conditions during the explosion, and for assuring the conformity of results with the requirements of individual standards.

The determined time intervals, necessary for the chamber type KV 150-M2 with the volume of 291 litres are shown in Figure 7.

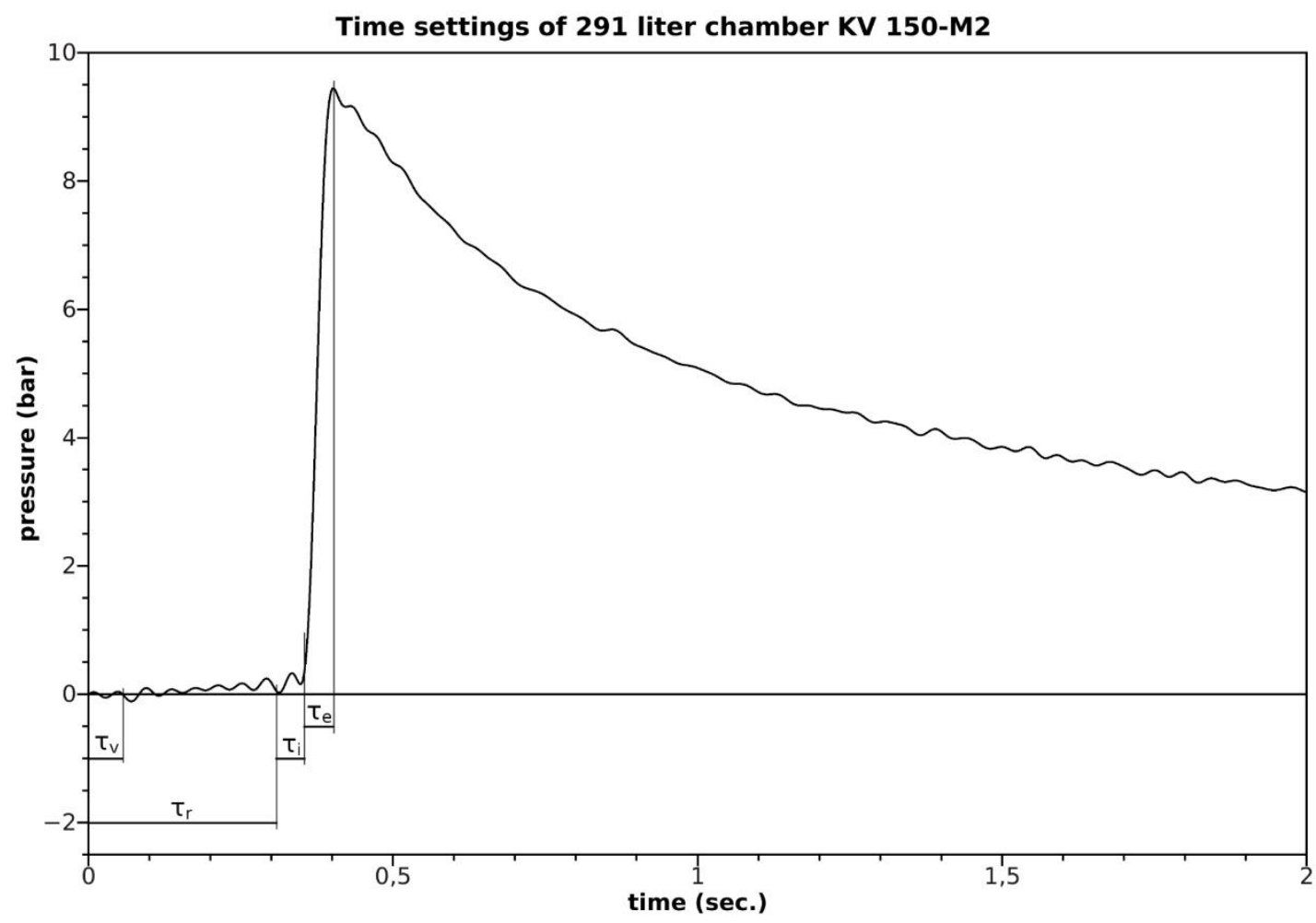

Figure 7 Timing parameters of the chamber

(time of dispersing start $\tau_{v}=54 \mathrm{~ms}$, time of igniter activation $\tau_{r}=320 \mathrm{~ms}$, time of dust, cloud ignition after igniter activation $\tau_{i}=45 \mathrm{~ms}$, time of attaining the maximum pressure at explosion since dust ignition $\tau_{e}=48 \mathrm{~ms}$ )

The procedure of measuring the timing parameters mentioned in this article is applicable for any size of vessels in the research and for the assessment of the risk of dust clouds explosions in the process industry.

Comparison of time interval of actuation of the dispersing and ignition system of KV 150-M2 chamber with the values given in the Standard is shown in Figure 8. The final formula is applicable for timing of the vessels of different volumes. 


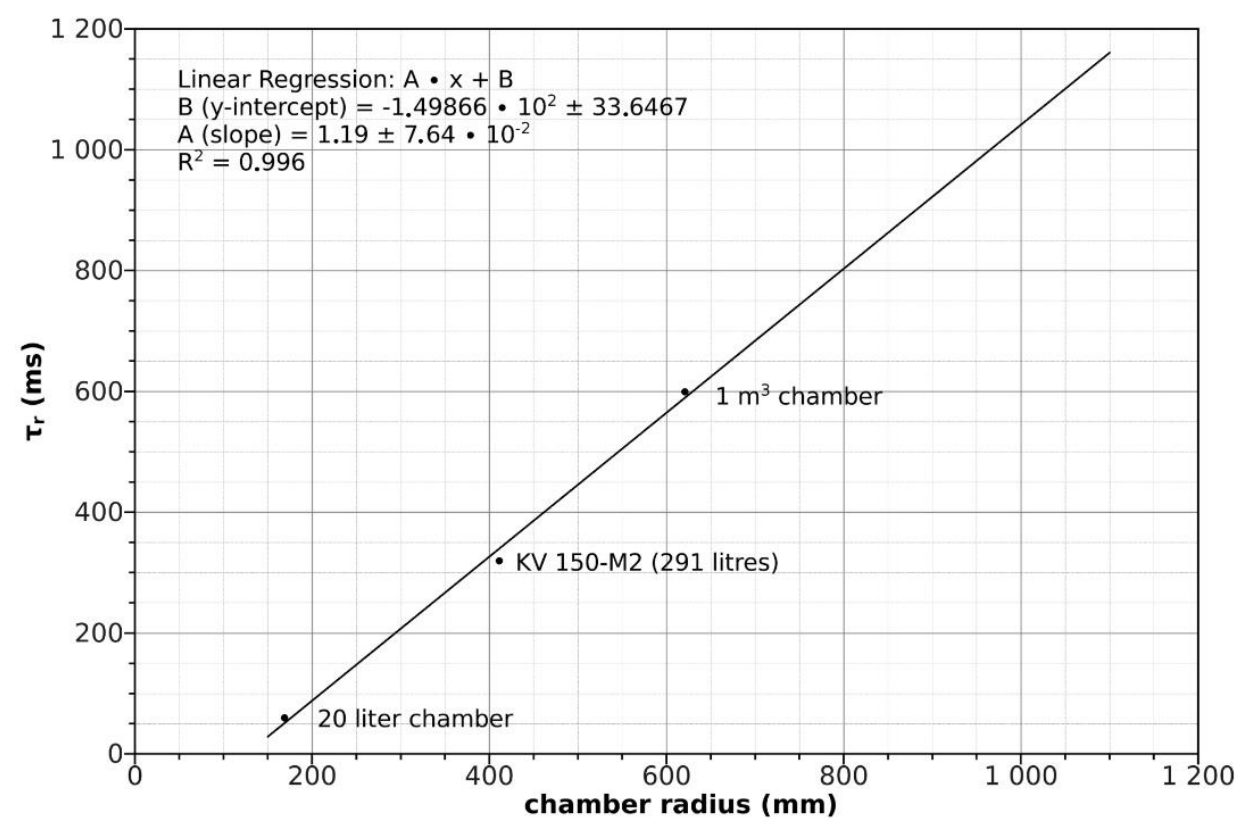

Figure 8 Comparison of time for igniter activation for the KV 150-M2 chamber with the Standard

It is evident from the graph, that, with increasing vessel volume, it is also necessary to increase the time interval between the activation of dispersing device and igniter. This is mainly due to the movement kinetics of dust particles, since they must overcome longer distance for making the ideal conditions for explosion.

\section{CONCLUSIONS}

The time parameters of the explosion chamber for the study of dispersed dusts are an important factor for the optimal functionality of the chamber. The time parameters have a fundamental influence on the value of $\mathrm{P}_{\max }, \mathrm{dP} / \mathrm{dt}$, and therefore also on $\mathrm{K}_{\text {st. }}$. The optimally set time delay of the igniter provides the correct explosion parameters of the dispersed dust. For the nitrocellulose igniter in the KV $150 \mathrm{M} 2$ chamber, the value of the activation delay is set to $320 \mathrm{~ms}$.

In addition to the igniter and disperser, other factors, such as the size and pressure of the compressed air vessel, the length of the disperser pipe and the design of the disperser, also affect the time parameters of the explosion chamber. Further research will focus on the influence of these factors on the time parameters of the explosion chamber.

\section{Acknowledgements}

The research was supported by the Slovak Research and Development Agency under the contract No. APVV-16-0223 and by the KEGA project 020STU-4/2021.

\section{References}

[1] TASCÓN, A. 2017. Design of silos for dust explosions: Determination of vent area sizes and explosion pressures. Eng. Struct., 134:1 - 10.

[2] ECKHOFF, R. K. 2009. Understanding dust explosions. the role of powder science and technology. J. Loss Prev. Process Ind., 22:105 - 116. 
[3] ECKHOFF, R. K. and FUHRE, K. 1984. Dust explosion experiments in a vented $500 \mathrm{~m} 3$ silo cell. J. Occupat. Accidents, 6:229 - 240.

[4] YUAN, Z., KHAKZAD, N., KHAN, F. and AMYOTTE, P. 2015. Dust explosions: A threat to the process industries. Process Saf. Environ., 98:57-71.

[5] LI, G., YANG, H.-X., YUAN, C.-M. and ECKHOFF, R. 2016. A catastrophic aluminium-alloy dust explosion in china. J. Loss Prev. Process Ind., 39:121 - 130.

[6] PROUST, C., ACCORSI, A. and DUPONT, L. 2007. Measuring the violence of dust explosions with the "20 1 sphere" and with the standard "iso $1 \mathrm{~m}^{3}$ vessel". Systematic comparison and analysis of the discrepancies. J. Loss Prev. Process Ind., 20:599 - 606.

[7] AJRASH, M. J., ZANGANEH, J. and B., M. 2016. Methane-coal dust hybrid fuel explosion properties in a large scale cylindrical explosion chamber. J. Loss Prev. Process Ind., 40:317 - 328.

[8] SCHEID, M., KUSCHE, C., SCHRDER, V. and BARTH, U. 2013. Tests on suitability of the ignition source "exploding wire" for the determination of explosion characteristics of combustible dusts in the 20-1-sphere. Chemical Engineering Transactions, 31:703 - 708.

[9] TASCÓN, A., RUIZ, A. and AGUADO, P. 2011. Dust explosions in vented silos: Simulations and comparisons with current standards. Powder Technol., 208:717 - 724.

[10] TASCÓN, A., RAMÍREZ-GOMEZ, A. and AGUADO, P. 2016. Dust explosions in an experimental test silo: Influence of length/diameter ratio on vent area sizes. Biosyst. Eng., 148:18 $-33$.

[11] ZHANG, Q. and ZHANG, B. 2015. Effect of ignition delay on explosion parametres of corn dust/air in confined chamber. J.Loss Prev. Process Ind., 33:23 - 28.

[12] CASHDOLLAR, K. and ZLOCHOWER, I. 2007. Explosion temperatures and pressures of metals and other elemental dust clouds. J. Loss Prev. Process Ind., 20:337 - 348.

[13] SERAFIN, J., BEBCAK, A., BERNATIK, A., LEPIK, P., MYNARZ, M. and PITT, M. 2012. The influence of air flow on maximum explosion characteristics of dust-air mixtures. J. Loss Prev. Process Ind., 26:209 - 214.

[14] BENEDETTO, A., GARCIA-AGREDA, A., RUSSO, P. and SANCHIRICO, R. 2012. Combined effect of ignition energy and initial turbulence on the explosion behavior of lean gas/dust-air mixtures. Ind. Eng. Chem. Res., 51:7663 - 7670.

[15] van der WEL, P. G. J. 1993. Ignition and propagation of dust explosions. dissertation, Technische Universiteit Delft, Delft.

[16] DAHOE, A. E., CANT, R. S. and SCARLETT, B. 2002. On the decay of turbulence in the 20-liter explosion sphere. Flow Turbul. Combust., 67:159- 184.

[17] EN 14034-3+A1:2011-08 (2011). En 14034-3+a1:2011-08. determination of explosion characteristics of dust clouds. part 3: Determination of the lower explosion limit LEL of dust clouds.

[18] KURACINA, R., PASTIER, M., BALOG, K. and TUREKOVÁ, I. 2013. Design of chemical igniter for chamber KV 150-M2. In Bezpečnost a ochrana zdraví při práci (Occupational Health and Safety), pages 59 - 61, Ostrava: SPBI.

\section{ORCID}

Zuzana Szabová $\quad$ 0000-0002-7886-1623

Richard Kuracina $\quad$ 0000-0003-1468-0820 